\title{
O desafio da paz. Contribuição das / às religiões: Alguns elementos iniciais
}

\author{
Marcio Ribeiro
}

\section{Resumo}

Atualmente, muitos apontam a contribuição das tradições religiosas como portadoras de uma mensagem de paz para a humanidade. Contudo, paz e religião parecem ser duas realidades de difícil convivência. Efetivamente, é mais comum o binômio violência e religião. Nos últimos anos vem se acentuando a relação entre violência e Deus, na qual a novidade não é tanto a religião ou suas práticas, mas a identidade violenta da própria divindade. $\mathrm{O}$ problema é justamente Deus, ou o "fator Deus".

Diante desse contra-senso, não há como negar a responsabilidade que as tradições religiosas tem nesse quadro. Não obstante, o fato de serem responsáveis faz com que as religiões possam contribuir com aquilo que lhes é peculiar. As experiências religiosas colocam o ser humano diante do desafio maior de nossa existência: a capacidade de dar respostas aos desafios que nos interpelam.

Nesta comunicação, vamos apresentar alguns pontos de nossa pesquisa sobre a reflexão teológica de René Coste. De modo mais especifico, vamos nos concentrar naquilo que esse teólogo vai denominar "hermenêutica da paz". Nossa intenção é mostrar como a "hermenêutica da paz" é um poderoso instrumental não só para a construção da paz como também para iluminar o diálogo religioso. 
Palavras-chave: Experiência Religiosa, Violência e Hermenêutica da Paz.

\begin{abstract}
Currently, many have noted the contribution of religious traditions as bearers of a message of peace for humanity. However, peace and religion appear to be realities with difficult to live together. In recent years has been emphasizing the relationship between violence and God in which the news is not so much religion or its practices, but the identity of the divinity itself violent. The problem is just God, or the "God factor".

Faced this paradox, there's no denying the responsibility that religious traditions have in that picture. Nevertheless, the fact of being responsible means that religions can contribute to what is peculiar to them. Religious experiences put a human being on the larger challenge of our existence: the ability to respond to the challenges that question us.

In this communication, we present some points of our research on Rene Coste theological reflection. Specifically, we focus on what this theologian will call "hermeneutics of peace." Our intention is to show how the "hermeneutics of peace" is not only a powerful instrument for building peace but also to illuminate the religious dialogue.
\end{abstract}

Keywords: Religious Experience, Violence and Hermeneutics of Peace.

\title{
Experiência religiosa e violência
}

É lugar comum afirmar que a realidade presente é marcada pela violência, em suas mais variadas formas, seja na esfera pública, seja nas relações interpessoais ou mesmo no mais íntimo da dimensão pessoal. ${ }^{1}$ Talvez por isso, muitos discursos enfatizam nossa época como mais violenta que as anteriores. ${ }^{2}$

\footnotetext{
${ }^{1}$ Centro Internacional de Investigação e Informação para a Paz (CIIIP); Universidade para a Paz das Nações Unidas. O estado da paz e a evolução da violência: a situação da América Latina. Tradução de Maria Dolores Prades. Campinas: Ed. UNICAMP, 2002. Luzia Fátima BAIERL. "A violência construindo novas configurações urbanas". In: Idem. Medo social: da violência visível ao invisível da violência. São Paulo: Cortez, 2004, pp 51-73. Jacques SÉMELIN. Purificar e destruir: usos políticos dos massacres e dos genocídios. Tradução de Jorge Bastos. Rio de Janeiro: DIFEL, 2009. Jean BAUDRILLAR, Edgard MORIN. A violência no mundo. Tradução de Leneide Duarte-Plon. Rio de Janeiro: Anima Editora, 2004.

${ }^{2}$ Wolfgang SOFSKY. Lère de l'émpouvant. Gallimard/Essais, 2002, p. 130-131. Citado por Paul VALADIER. «Violence et monothéismes ». Étvdes. Revue de culture contemporaine. Paris, Tome
} 
O fato é que hoje, talvez mais que ontem, temos a coragem de visibilizar o que antes estava oculto, bem como identificar sua tipologia. ${ }^{3}$ Ao mesmo tempo, surgem diversas tentativas de explicar o que seja esse homo violens. ${ }^{4}$ Entre tantas que buscam causas na constituição biológica do ser humano, em fatores sociais ou ainda em fatores psicológicos, ${ }^{5}$ há aquelas que colocam na própria experiência religiosa a origem e a causa da violência humana. ${ }^{6}$

Em um artigo sobre a religião como solução para o problema da violência, Jose M. Castillo percebe como na história da humanidade o fator religioso está, de modo geral, relacionada com a questão da violência.

O fato brutal da violência, que tantas vezes foi desencadeado (e continua sendo) pelas religiões nesse mundo, nos obriga a repensar a relação entre religião e violência. E, por mais que as religiões e os 'homens da religião' preguem a paz, a concórdia e o amor, todos sabemos de sobra que, com demasiada freqüência, o fator religioso é um determinante fundamental das agressões que os seres humanos cometem uns contra os outros. (...) Em qualquer caso, falar da violência sem fazer menção à religião é afrontar uma questão que, não somente ficaria incompleta, mas que, além disso, nunca chegaríamos a suas últimas raízes. ${ }^{7}$

Na realidade, para Castilho o problema está na absolutização da própria religião em detrimento do valor fundamental da vida. Entra em jogo a questão do fanatismo e do fanático como aquele que ao sacralizar um aspecto da

398, n. 6 (3986), p. 755-764, juin, 2003, p. 755. Valadier fala da impressionante "proliferação da violência", cuja lista fatos faz-nos perder o fôlego.

${ }^{3}$ Cf. CIIIP. O estado da paz e a evolução da violência, p. 21-36.

${ }^{4}$ Segundo Roger DANDOUN, a violência seria uma característica primordial e essencial, constitutiva do ser humano, de modo que ele é intrínseca e fundamentalmente definido e estruturado por ela. A violência: ensaio acerca do homo violens. Rio de Janeiro: DIFEL, 1998, p. 8

${ }^{5}$ Cf. Yves MICHAUD. A violência. São Paulo: Ática, 1989, pp. 70-114. Leonel NARVÁEZ GOMES. "A reconciliação: para prevenir a violência e construir a paz duradoura". In: Centro Loyola de Fé e Cultura; Fundação Konrad Adenauer. Cultura da paz e prevenção da violência. São Paulo: Loyola, 2003, pp. 15-27.

${ }^{6}$ Roger DANDOUN. A violência, p. 14-22. Cf. Faustino do Couto TEIXEIRA. "Diálogo inter-religioso: o desafio da acolhida do outro". In: Maria Clara L. BINGEMER; Paulo Fernando C. de ANDRADE. O mistério e a história: ensaios de teologia em homenagem ao Pe. Félix Pastor por ocasião dos seus 70 anos. São Paulo: Loyola, 2003, p. 49s. Muito sugestivo é o título da obra de Jessica STERN. Terror em nome de Deus: por que os militantes religiosos matam. São Paulo: Editora Barcarolla, 2004.

${ }^{7}$ José M. CASTILLO. “¿Sirve la religión para resolver el problema de la violencia?” Exodo, Centro Evangelio y Liberación. Madrid, n. 57, enero-febrero, 2001, p. 4-10.p. 48. 
realidade o absolutiza e o torna excludente de tudo aquilo que não o é. ${ }^{8}$ Assim, na medida em que a própria vida é posta em segundo plano, ela é suplantada pela religião e o fanático assume um posicionamento violento para defendê-la como um valor absoluto em si mesmo.

Esse fenômeno revela uma visão religiosa negadora da alteridade. Nesse sentido, surgem teorias mais críticas que apontam as tradições religiosas monoteístas como as mais propensas ao uso da violência e, como tal, responsáveis pelo seu o aumento indiscriminado, na esfera religiosa e em geral. ${ }^{9} \mathrm{O}$ monoteísmo é visto como uma negação da diversidade. Comparado com o politeísmo que aceita a diversidade de seres divinos, o monoteísmo age como uma força negadora do diferente, impondo despótica e tiranicamente sua crença e sua verdade que se tornam tão absolutas quanto à própria religião. ${ }^{10}$

\section{Deus e violência}

Pensadores como René Girard e Mircea Eliade refletem sobre a relação entre religião e violência e sua função nas sociedades. Mas, se esses autores refletem de um modo positivo, outros não. No Tratado de ateologia,${ }^{11}$ Michel Onfray coloca a "pulsão de morte" como a origem da religião e como o combustível que alimenta os três monoteísmos. Essa pulsão, quando é direcionada para dentro do movimento religioso, provoca as patologias de autodestruição; quando se volta para fora, engendra a agressão, a violência, os crimes e os assassínios.

A religião do Deus único esposa esses movimentos: trabalha pelo ódio a si mesmo, pelo desprezo do próprio corpo, pelo descrédito da inteligência, pela desconsideração da carne, pela valorização de tudo o que nega a subjetividade desenvolvida; projetada contra o outro, fomenta o desprezo, a maldade, a intolerância que produzem os racismos, a xenofobia, o colonialismo, as guerras, a injustiça social. Basta observar a História para constatar a miséria e os rios de sangue derramados em nome do Deus único...

\footnotetext{
${ }^{8}$ Idem, p. 54.

${ }^{9}$ Sobre esse fato ver: Paul VALADIER. Violence et monothéismes.

${ }^{10}$ Ver as relações entre monoteísmo e poder no numero monográfico de Concilium 197 / 1 1985/ 1: teologia fundamental. Petrópolis: Vozes (O Monoteísmo)

${ }^{11}$ Traité d'athéologie. Paris: Grasset \& Fasquelle, 2005. Edição brasileira: Tratado de ateologia: física da metafísica. Tradução de Môncia Stahel. São Paulo: WMF Martins Fontes, 2007.
} 
Além da pulsão de morte, outra característica seria o ódio, de modo que:

Os três monoteísmos, animados por uma mesma pulsão de morte genealógica, partilham uma série de desprezos idênticos: ódio da razão e da inteligência; ódio da liberdade; ódio de todos os livros em nome de um único; ódio da vida; ódio da sexualidade; das mulheres e do prazer; ódio do feminino; ódio do corpo, dos desejos, das pulsões. (...) Equivale a dizer a vida crucificada e o nada celebrado. ${ }^{12}$

O fato mais crítico é que, segundo alguns, o cristianismo seria a face mais violenta dentro das tradições monoteístas. ${ }^{13}$ Uma mirada na história da civilização ocidental, cujo desenvolvimento é profundamente marcado pela influência do cristianismo, percebemos uma cultura de violência, na dualidade do fanatismo e intolerância, ${ }^{14}$ externa e internamente. ${ }^{15}$

Essa relação (ligação) entre a violência e o cristianismo não pára nele. Ela vai mais longe e atinge a própria imagem do Deus cristão. A justificativa para essa postura, em se tratando de uma postura religiosa, é a própria imagem de Deus. Ou seja, uma religião violenta reflete o Deus violento. ${ }^{16}$ Causa espanto o sadismo de uma imagem de um deus que só se contenta com o sangue do inocente para aplacar sua ira e seu desejo de vingança. ${ }^{17}$

A resposta a essa questão passa não somente pela superação dessa imagem deturpada de Deus. Não basta apenas afirmar que Deus não é violento. É necessário positivamente e demonstrar todo o alcance da proposta de paz da Revelação cristã. É necessário estabelecer a relação essencial entre a paz e o Mistério trinitário de Deus, revelado em Jesus Cristo.

\footnotetext{
${ }^{12}$ Idem, p.52s.

${ }^{13}$ Paul VALADIER, art. cit., p. 758.

${ }^{14}$ Ver Marcos Antônio LOPES, Marcos Lobato MARTIS. A peste das almas: histórias de fanatismos. Rio de Janeiro: Editora FGV, 2006.

${ }^{15}$ Sobre essa questão, ver Maria Clara L. BINGEMER (org.) Violência e Religião: Cristianismo, Islamismo, Judaísmo: três religióes em confronto e diálogo. Rio de Janeiro: Ed. PUC-Rio; São Paulo: Loyola, 2001.

${ }^{16}$ Como conclui categoricamente Salman RUSHDIE “O nome do problema é Deus" ao analisar o problema da violência na Índia. Ou ainda o "Fator Deus" de Jose SARAMAGO como causa da violência. Cf., respectivamente, O nome do problema é Deus. Folha de São Paulo, São Paulo, 17 mar. 2002, p.29. Disponível em: <http://www1.folha.uol.com.br/folha/mundo/ult94u38501. shtml $>$. Último acesso 10 de maio de 2011. O fator Deus. Folha de São Paulo, São Paulo, 19 set. 2001. Disponível em: <http://www1.folha.uol.com.br/folha/mundo/ult94u29519.shtml>. Último acesso em 10 de maio de 2011.

${ }^{17}$ Sintomático é o título da obra de François VARONE. Ce Dieu censé aimé la souffrance. Paris: Les Édiotions du Cerf, 1993, cuja tradução em espanhol tem como titulo El Dios sádico (em português, Esse Deus que dizem amar o sofrimento. Aparecida, SP: Santuário, 2001).
} 


\section{Teologia, violência e paz}

No quadro atual da produção teológica sobre essa experiência religiosa violenta, bem como sobre a superação dessa imagem de Deus, vale destacar a reflexão de teólogos como Andrés Torres Queiruga, François Varone, Giuseppe Barbaglio e Jose Maria Mardones. ${ }^{18}$ Cada autor se dedica a abordar a questão a partir de um determinado contexto, seja bíblico, pastoral ou filosófico.

É interessante notar que a produção teológica sobre essa temática vem crescendo. A recente publicação de algumas obras demonstram esse fato. ${ }^{19}$ Contudo, ainda é incipiente um tratamento mais sistemático dessa questão. Por essa razão, vale destacar o nome do teólogo René Coste, ${ }^{20}$ cuja produção teológica tem demonstrado seu interesse por esse tema e sua contribuição para um desenvolvimento teológico sobre o tema da paz. ${ }^{21}$

\section{A experiência religiosa cristã: a paz como centro do mistério salvífico}

Para René Coste a paz é um tema central na mensagem do Evangelho. $\mathrm{Na}$ verdade, ela é uma de suas características essenciais. Em todo o Novo Testamento, a paz é o que define a própria salvação. ${ }^{22} \mathrm{O}$ Novo Testamento,

${ }^{18}$ Andrés TORRES QUEIRUGA. Do terror de Isaac ao Abbá de Jesus: por uma nova imagem de Deus. São Paulo: Paulinas, 2001. François VARONE. Esse Deus que dizem amar o sofrimento. Aparecida, SP: Santuário, 2001. Giuseppe BARBAGLIO. Dios ¿violento? Lecturas de las Escrituras hebreas y cristianas. Navarra: Verbo Divino, 1992. José María MARDONES. Matar a nuestros dioses: um Dios para um creyente adulto. 2a ed., Madrid: Editorial PPC, 2007.

${ }^{19}$ Como exemplo citamos Alfons FÜRST (org.). Paz na terra: as religiões universais entre a renúncia e a disposição à violência. São Paulo: Idéias e Letras, 2009; Jean-Daniel CAUSSE; Élian CUVILLIER; André WÉNIN. Divine violence: approche exégétique et anthropologique. Paris: Les Éditions Du Cerf; Médiaspaul, 2011. Gerlinde BAUMANN. Entender as imagens divinas da violência no Antigo Testamento. Tradução de Milton Camargo Mota. São Paulo: Loyola, 2001.

${ }^{20}$ René COSTE, padre de Saint-Sulpice, é professor honorário da faculdade de teologia do Instituto Católico de Toulouse, ex-presidente da organização Pax Christi-France e antigo consultor do Pontifício Conselho Justice e Paz e do Pontifício Conselho pelo diálogo com os não cristãos. Trabalha ativamente no diálogo ecumênico e inter-religioso, pela promoção da paz e da justiça e da salvaguarda da Criação. É especialista em teologia social e no Ensino Social da Igreja. Possui várias pesquisas fundamentais nas áreas de ética social e da paz.

${ }^{21}$ Citamos aqui as obras que abordam diretamente o tema da paz: Dynamique de la paix. Paris: Desclée. 1965. L’Eglise et la paix. Paris: Desclée. 1979. Paix, justice, gérance de la création. Paris: Nouvelle Cite. 1989. Il est nostre paix. Paris: Les Éditions Ouvrières, 1991. Théologie de la paix. Paris: Les Éditions du Cerf. 1997. «Le renouveau de la théologie de la paix dans léglise catholique au cours du XXe siècle ». In: Centre d'études d'histoire de la Défense. Penser la paix. Cycle de conférences sur le thème Penser la paix 1999-2000.

${ }^{22}$ Cf. René COSTE. Théologie da la paix, p. 118. 
em diversas ocasiões, nos testifica essa relação íntima entre a paz e o evento Cristo. ${ }^{23}$ Em a sua atividade como Messias Salvador, a paz coloca-se como um elemento do Reino e como testemunho de sua vinda. ${ }^{24}$ Ela se situa no centro de sua pregação, e torna-se a expressão do dom do Ressuscitado à Igreja e toda humanidade. ${ }^{25}$ Essa relação com o Messianismo de Jesus é que confere à paz os matizes teológicos que nos permitem desenvolver uma reflexão sistemática sobre a paz como elemento fundamental da fé e da salvação cristãs. ${ }^{26}$ Essa centralidade da paz no mistério salvífico é o fundamento do que René Coste denomina de "a hermenêutica da paz". Assim sendo, partindo do texto de Ef 2,14-18, Coste traça uma relação entre a paz e o Mistério Pascal.

É ele, com efeito, que é a nossa paz: do que era dividido, fez uma unidade. Em sua carne destruiu o muro da separação: o ódio. Ele aboliu a lei e os mandamentos com suas observâncias. Ele quis assim, a partir do judeu e do pagão, criar em si mesmo um só homem novo, estabelecendo a paz, e reconciliá-lo com Deus, ambos em um só corpo, por meio da cruz, onde ele matou o ódio. Ele veio anunciar a paz a vós que estáveis longe, e a paz aos que estavam perto. E é graças a ele que uns e outros, num só Espírito, temos acesso ao Pai.

Para René Coste estamos diante de uma extraordinária sinfonia de paz, de amor, de unidade, de reconciliação:

Em algumas linhas, que extraordinária sinfonia da Paz (ele que é nossa paz... fez entre eles a paz... proclamou a paz...), de Amor (destruindo o muro que os separava, suprimindo em sua carne o ódio... em si mesmo ele matou o Ódio), de Unidade (ele que de dois fez um povo... um só Homem novo... um só Espirito), de Reconciliação pela Cruz e de Redenção (na qual as Três divinas Pessoas estão engajadas). ${ }^{27}$

${ }^{23}$ Cf. V. HASLER. eirene. In: H. BALZ, G. SCHNEIDER (eds.). Diccionario Exegetico del Nuevo Testamiento I. Salamanca: Sigueme, 1996, col. 1201. Os contextos são: como o dom ou fruto do Espírito Santo que conduz a Cristo ( $\mathrm{Rm}$ 8,6; Gl 5,22; Ef 4,3); como a designação "Evangelho da paz" (At 10,36; Ef 2,17; 6,15); relacionada ao próprio Jesus (Ef 2,14.15); Como paz com Deus ou paz em Deus (Rm 5,1; 15,33; 16,20; 1Cor 7,15; 14,33; 2Cor13,11; Fl 4,9; 1Ts 5,23; Hb 13,20); Designando o Reino de Deus como "Reino de paz" (Rm 14,17); como saudação epistolar, onde a graça e a paz são como dons recebidos "da parte de Deus nosso Pai e do Senhor Jesus Cristo" (Rm 1,7; 1Cor 1,3; 1Pd 1,2; Ap 1,4; 2 Cor 1,2; Gl 1,3; Ef 1,2; Fl 1,2; Cl 1,2; 1Ts 1,1; 2 Ts 1,2; 1Tm 1,$2 ; 2 \mathrm{Tm} 1,2 ; \mathrm{Tt} 1,4 ; \mathrm{Fm} \mathrm{1,3;2Pd} \mathrm{1,2;} \mathrm{2Jo} \mathrm{3)}$

${ }^{24}$ Cf. Walter KASPER. Jesus, el Cristo. Salamanca: Sigueme, sexta edición, 1986, p. 87-88.

${ }^{25}$ René COSTE, Il est nostre paix, p. 81

${ }^{26}$ Cf. idem, p. 82

${ }^{27}$ Idem, p. 10 (tradução livre). 
O texto de Ef é uma "surpreendente síntese do Mistério Pascal", cujo ponto central é a paz. Ela é a temática fundamental, e o Mistério Pascal, em sua inseparável globalidade (Paixão, Ressurreição, Pentecostes) é todo inteiro reinterpretado. ${ }^{28}$

Há, portanto, uma relação essencial entre a paz e o Mistério Pascal, de tal modo que ambos recebem novos matizes a partir dessa própria relação, isto é, o Mistério pascal dá o sentido propriamente cristão da paz; por outro lado, ela abre nossos olhos para toda intensidade salvífica-existencial do Mistério Pascal. Pode-se, a partir dessa relação, falar de uma hermenêutica da paz como uma chave de interpretação do Mistério salvífico cristão. ${ }^{29}$

\section{A hermenêutica da paz}

Para perceber a profundidade dessa hermenêutica da paz, o caminho proposto por René Coste é seguir numa leitura atenta as narrativas do Mistério Pascal, tal como eles nos são apresentados, ${ }^{30}$ tendo como pano de fundo a paz. Para tanto, ele elege a narrativa "discípulos de Emaús", na qual Jesus, "começando por Moisés e todos os profetas, lhes explicou em todas as Escrituras o que lhe concernia" (Lc 24,27). Nas palavras de René Coste, "O Ressuscitado Hermeneuta, Exegeta, Intérprete de seu próprio mistério Pascal". ${ }^{31}$ Fato que não é uma novidade, já que durante seu ministério público, Jesus constantemente interpretava a Lei a partir de um sentido fundamentalmente novo, tirado das profundezas da Palavra de Deus ou de sua própria criatividade no Espírito. Igualmente, esclarecia constantemente sua própria missão, bem como a Aliança entre Deus e seu povo, sem a adulterar ou deturpar em nada, mas a superando de um modo freqüentemente desconcertante à primeira vista, mas que provocava o assombro e entusiasmo, quando a inteligência e o coração dos ouvintes ficavam abertos à Novidade de Deus? ${ }^{32}$

Essa postura hermenêutica está presente em todo o Novo Testamento, como uma reinterpretação radical do Antigo, ambos como Palavra de Deus, inseridos numa mesma história de fé. $\mathrm{E}$ a clave $^{33}$ para essa reinterpretação

\footnotetext{
${ }^{28}$ Idem, ibidem.

${ }^{29}$ Idem, p. 12.

${ }^{30}$ Idem, p. 11.

${ }^{31}$ Idem, p. 12.

${ }^{32}$ Idem, p. 13.

${ }^{33} \mathrm{O}$ termo clave tem um sentido mais propriamente hermenêutico que chave. Assim prefere Juan Luiz SEGUNDO, seja para falar da pregação de Jesus, seja do pensamento de Paulo sobre
} 
é o evento Jesus "a partir da novidade inaudita da atividade e das palavras, da Paixão, da Morte e da Ressurreição desse Jesus, cujo Mistério ao mesmo tempo divino e humano não cessamos de aprofundar". ${ }^{34}$

O centro vital da hermenêutica bíblica está no fato dela não se tratar simplesmente de um processo intelectivo, mas sim de uma "dinâmica de vida".

Não é por curiosidade intelectual que os documentos do passado bíblico são sem cessar meditados e reinterpretados pelas testemunhas da Revelação, mas para deles viver: para lá encontrar o Sentido, para se orientar dentro de sua própria existência, para saber como pensar e como agir. Por que tal atitude? Pois que os crentes do AT e do NT estavam convencidos que os textos do passado lhes transmitiam a autêntica Palavra de Deus e que esta Palavra era definitiva sempre viva e sempre atual, sempre presente como Sol sem eclipse, pois ela era a Palavra da Vida, do Criador, do Senhor da história, d'Aquele que vela amorosamente sobre aqueles e aquelas que nele depositaram confiança. $O$ passado da divina Palavra torna-se o presente daqueles e daquelas que a meditam, mas também seu futuro, já que eles ai encontraram a bússola que vai thes permitir avançar. ${ }^{35}$

Estamos diante de um amplo horizonte hermenêutico, cujos elementos são a comunhão com Deus e com suas testemunhas, a inserção em uma corrente de fé e de espiritualidade, em uma história iluminada pela palavra ação de Deus. Destarte, "a Bíblia toda inteira é assim a Hermenêutica inesgotável da Divina Palavra." 36

Essa concepção de hermenêutica é a base do trabalho do teólogo, ou seja, um trabalho que se apóia em uma exegese séria, consciente da vitalidade da Palavra de Deus e da necessária interpretação para os nossos dias, unindo rigor intelectual, abertura aos problemas atuais e à ação do Espírito. ${ }^{37}$

Esta é na realidade a tarefa da teologia e do teólogo hermeneuta. Sem abrir mão do rigor intelectual, dos princípios metodológicos da exegese da e produção teológica comprometida com sua história, ele não é somente um cientista, mas antes de tudo, um crente. E como tal, é um ouvinte, seja da palavra humana, seja da Palavra divina. "Sem isso, como poderá ele interpretar validamente a Palavra de Deus a serviço de seus contemporâneos?". ${ }^{38}$

a história de Jesus. Cf. A história perdida e recuperada de Jesus de Nazaré: dos Sinóticos a Paulo. Tradução de Magda Furtado de Queiroz. São Paulo: Paulus, 1997.

${ }^{34}$ René COSTE, Il est notre paix, p. 13.

${ }^{35}$ Idem, ibidem. O grifo é do autor.

${ }^{36}$ Idem, p. 15.

${ }^{37}$ Idem, p. 16.

${ }^{38}$ Idem, ibidem. 
Esse pano de fundo hermenêutico é fundamental para o empreendimento proposto por René Coste, o de "reencontrar por uma reflexão pessoal a hermenêutica da paz aplicada ao Mistério Pascal e a partir dela reelaborar para o hoje que é o nosso" ${ }^{39}$ Nesse sentido, segundo René Coste, o autor de Efésios interpretou o Mistério pascal utilizando como chave de leitura a hermenêutica da paz. Com isso, pode dar uma resposta aos seus ouvintes dentro de seu contexto. A tarefa proposta agora é reelaborar essa aplicação para os nossos dias..$^{40}$

Destarte, além uma clara compreensão da metodologia própria da hermenêutica teológica, segundo a dinâmica bíblica vista acima, é necessária, também, uma clara visão do conceito de paz. Para tanto, é necessário um questionamento sobre a compreensão contemporânea da paz, da percepção do que a ameaça, dos temores e das aspirações que cercam a humanidade. Este é um quadro demasiado plural. Para René Coste, há alguns elementos fundamentais para essa correta visão. ${ }^{41}$

Por outro lado, devemos reconhecer que muitas pessoas hoje começam a compreender que as ameaças à paz, à justiça e ao meio ambiente estão interconectadas $^{42}$ e que a promoção da paz deve estar aliada a uma tomada de consciência da mais alta importância, bem como da necessária integração das culturas e, principalmente das religiões, cujo movimento ecumênico se faz promotor. ${ }^{43}$ Por esses motivos, René Coste constata que "a concepção contemporânea da paz é plural e contraditória", possuidora de "uma riqueza potencial incontestável" ${ }^{44}$ e que diante dela é indispensável um claro discernimento.

Um bom exemplo é a compreensão da paz como integridade (ou salvaguarda) da criação. Nesse sentido, ela está estreitamente ligada à questão atual do desenvolvimento sustentável, não só com relação ao meio ambiente, mas, principalmente, com relação aos seres humanos excluídos de um determinado modelo econômico. Por isso, para que o termo integridade esteja mais próximo do ponto de vista bíblico, deve estar aliado à idéia de gerência ou intendência da criação, "conceitos mais fecundos para a problemática contemporânea". ${ }^{45}$

\footnotetext{
${ }^{39}$ Idem, p. 17.

${ }^{40}$ Idem, ibidem.

${ }^{41}$ Cf. idem, ibidem.

${ }^{42}$ Idem, p. 21. Vale notar que R. Coste possui uma obra específica sobre essa questão: Paix, Justice, Gérance de la Criéation, Paris, Nouvelle Cite, 1989.

${ }^{43}$ René Coste, Il est notre paix, p. 18.

${ }^{44}$ Idem, ibidem.

${ }^{45}$ Idem, p. 21.
} 


\section{Hermenêutica da paz e diálogo religioso}

Diante do desafio de superar animosidades religiosas, ${ }^{46}$ a hermenêutica da paz pode ser uma luz para um caminho de construção e promoção diálogo religioso em nome da paz. A paz como chave hermenêutica da experiência religiosa é o ponto fundamental para falarmos da paz entre as religiões.

O pressuposto de Hans Küng - a paz entre as religiões é condição para a paz mundial - nos instiga a questionar: onde está essa paz, a paz entre as religiões? Qual é seu na configuração e na lógica da experiência religiosa, entendida como resposta a proposta de Deus e como ação propositiva ao outros (ao outro humano, a toda a criação).

A perspectiva de Küng é mais complexa, conforme ele mesmo resume conclusivamente em quatro sentenças:

- Nenhuma paz entre as nações sem paz entre as religiões.

- Nenhuma paz entre as religiões sem diálogo entre as religiões.

- Nenhum diálogo entre as religiões sem padrões éticos globais.

Nenhuma sobrevida do nosso Globo na paz e justiça sem um novo paradigma de relações internacionais na base de padrões éticos globais. ${ }^{47}$

Tudo depende de um novo ethos. Mas qual seria esse novo ethos. Melhor. Qual seria seu fundamento? Dissemos acima que o ethos humano violento é espelho de uma imagem do Deus violento, isso nos pode levar a uma aporia: quem depende de quem? O que depende do que?

Qual a solução dessa aporia? Qual a saída desse círculo mimético de violência? A resposta só pode ser uma, mesmo correndo o risco de ser contraditório: é a paz.

A questão é que a paz entre as religiões está condicionada com a capacidade de dialogar com o outro, com outra experiência religiosa. Muito se fala sobre diálogo. Não obstante, corremos o risco de permanecermos em um "monólogo a dois". O diálogo entre experiências religiosas é um desafio. Mas seu desafio maior está em reconhecer seu verdadeiro objetivo: a paz.

De fato, a história humana nos revela que as tradições religiosas nem sempre tiveram a capacidade de dialogar. Em muitos momentos foram elas que motivaram conflitos e guerras. O diálogo entre as religiões é um desafio.

\footnotetext{
${ }^{46}$ Cf. Faustino do Couto TEIXEIRA. Diálogo inter-religioso: o desafio da acolhida do outro, p. 49s.

${ }^{47}$ Cf. Hans KÜNG. Religiões no mundo: em busca dos pontos comuns. Tradução Carlos Almeida Pereira. Campinas: Verus Editora, 2004, p. 16. Ver também "Religiões mundiais e Ethos Mundial". Cadernos de Teologia Pública. São Leopoldo: UNISINOS. Ano IV, nº 33, 2007.
} 
Mas é possível que na medida em que as religiões busquem pontos em comum, esse diálogo tão necessário cresça. Muito mais ainda, na medida em que as religiões favoreçam uma verdadeira experiência religiosa de "renuncia à violência" ${ }^{" 48} \mathrm{e}$ tomem a paz como paradigma. ${ }^{49}$

\section{Referências Bibliográficas}

BAIERL, Luzia Fátima. "A violência construindo novas configurações urbanas". In: Idem. Medo social: da violência visivel ao invisivel da violência. São Paulo, Cortez, 2004, pp. 51-73.

BARBAGLIO, Giuseppe. Dios ¿violento? Lecturas de las Escrituras hebreas $y$ cristianas. Navarra, Verbo Divino, 1992.

BAUDRILLAR, Jean; Edgard MORIN. A violência no mundo. Tradução de Leneide Duarte-Plon. Rio de Janeiro, Anima Editora, 2004.

BAUMANN, Gerlinde. Entender as imagens divinas da violência no Antigo Testamento. Tradução de Milton Camargo Mota. São Paulo, Loyola, 2001. BINGEMER, Maria Clara L. (org.) Violência e Religião: Cristianismo, Islamismo, Judaísmo: três religiões em confronto e diálogo. Rio de Janeiro, Ed. PUC-Rio; São Paulo, Loyola, 2001.

CASTILLO, José M. “¿Sirve la religión para resolver el problema de la violencia?” Exodo, Centro Evangelio y Liberación. Madrid, n. 57, enerofebrero, 2001, p. 4-10.

Centro Internacional de Investigação e Informação para a Paz (CIIIP); Universidade para a Paz das Nações Unidas. O estado da paz e a evolução da violência: a situação da América Latina. Tradução de Maria Dolores Prades. Campinas, Ed. UNICAMP, 2002.

COSTE, René. Il est nostre paix. Paris, Les Éditions Ouvrières, 1991.

COSTE, René. Théologie da la paix. Paris, Les Éditions du Cerf. 1997.

DANDOUN, Roger. A violência: ensaio acerca do homo violens. Rio de Janeiro, DIFEL, 1998.

FÜRST, Alfons (org.). Paz na terra: as religiões universais entre a renúncia e a disposição à violência. São Paulo, Idéias e Letras, 2009.

HASLER, V. "eirene”. In: BALZ, H.; SCHNEIDER, G. (eds.). Diccionario

${ }^{48}$ Cf. Alfons FÜRST (org.). Paz na terra, p. 13.

${ }^{49}$ René Coste entende paradigma da paz como algo que vital para a "autenticidade cristã". Cf.

Théologie da la paix, p. 412. 
Exegetico del Nuevo Testamiento I. Salamanca, Sigueme, 1996, col. 1201. KASPER, Walter. Jesus, el Cristo. Salamanca, Sigueme, sexta edición, 1986. KÜNG, Hans. "Religiões mundiais e Ethos Mundial". Cadernos de Teologia Pública. São Leopoldo, UNISINOS. Ano IV, nº 33, 2007.

KÜNG, Hans. Religiões no mundo: em busca dos pontos comuns. Tradução Carlos Almeida Pereira. Campinas, Verus Editora, 2004.

LOPES, Marcos Antônio; MARTIS, Marcos Lobato. A peste das almas: histórias de fanatismos. Rio de Janeiro, Editora FGV, 2006.

MARDONES, José María. Matar a nuestros dioses: um Dios para um creyente adulto. $2^{\mathrm{a}}$ ed., Madrid, Editorial PPC, 2007.

MICHAUD, Yves. A violência. São Paulo, Ática, 1989.

NARVÁEZ GOMES, Leonel. "A reconciliação: para prevenir a violência e construir a paz duradoura". In: Centro Loyola de Fé e Cultura; Fundação Konrad Adenauer. Cultura da paz e prevenção da violência. São Paulo, Loyola, 2003, pp. 15-27.

ONFRAY, Michel. Tratado de ateologia: física da metafísica. Tradução de Mônica Stahel. São Paulo, WMF Martins Fontes, 2007.

RUSHDIE, Salman. O nome do problema é Deus. Folha de São Paulo, São Paulo, p. 29, 17 de março de 2002, Disponível em: <http://www1.folha.uol. com.br/folha/mundo/ult94u38501.shtml $>$. Acesso em 10 de maio de 2011.

SARAMAGO, Jose. O fator Deus. Folha de São Paulo, São Paulo, 19 de setembro de 2001. Disponível em: $<\mathrm{http} / / \mathrm{www} 1$.folha.uol.com.br/folha/ mundo/ult94u29519.shtml $>$. Acesso em 10 de maio de 2011.

SEGUNDO, Juan Luiz. A história perdida e recuperada de Jesus de Nazaré: dos Sinóticos a Paulo. Tradução de Magda Furtado de Queiroz. São Paulo, Paulus, 1997.

SÉMELIN, Jacques. Purificar e destruir: usos politicos dos massacres e dos genocídios. Tradução de Jorge Bastos. Rio de Janeiro, DIFEL, 2009.

SOFSKY, Wolfgang. L'ère de l'émpouvant. Paris, Gallimard/Essais, 2002.

TEIXEIRA, Faustino do Couto. "Diálogo inter-religioso: o desafio da acolhida do outro". In: BINGEMER, Maria Clara L.; ANDRADE, Paulo Fernando C. de. O mistério e a história: ensaios de teologia em homenagem ao Pe. Félix Pastor por ocasião dos seus 70 anos. São Paulo, Loyola, 2003, pp. 49-74.

TORRES QUEIRUGA, Andrés. Do terror de Isaac ao Abbá de Jesus: por uma nova imagem de Deus. São Paulo, Paulinas, 2001. 
VALADIER, Paul. "Violence et monothéismes". Étvdes. Revue de culture contemporaine. Paris, Tome 398, n 6 (3986), p. 755-764, juin, 2003.

VARONE, François. Esse Deus que dizem amar o sofrimento. Aparecida, Santuário, 2001.

\section{Marcio Ribeiro}

Professor do Departamento de Teologia da Universidade Santa Úrsula.

Mestre em Teologia Sistemático Pastoral pela PUC-Rio. Aluno do Programa de Pós Graduação (doutorado) na mesma instituição. E-mail: mhribeiro@uol.com.br

Artigo Recebido em 29/08/2011

Artigo Aprovado em 30/11/2011 